\title{
TLR4 and TLR8 variability in Amazonian and West Indian manatee species from Brazil
}

Tatiana Maia de Oliveira ${ }^{1}$ (D), Tibério Cesar Tortola Burlamaqui ${ }^{1}(\mathbb{D})$, André Luiz Alves de Sá ${ }^{1,2} \mathbb{D}^{(\mathbb{D}}$, Breanna Breaux ${ }^{3}$ (D), Fábia de Oliveira Luna ${ }^{4}$ (D), Fernanda Löffler Niemeyer Attademo $0^{5,6}$ (D), Alex Garcia Cavalleiro de Macedo Klautau ${ }^{7}$ (D), Jairo Moura Oliveira ${ }^{8}$ (D), Leonardo Sena ${ }^{1}$ (D), Michael F. Criscitiello ${ }^{3,9}$ (D) and Maria Paula Cruz Schneider ${ }^{1}$

${ }^{1}$ Universidade Federal do Pará, Instituto de Ciências Biológicas, Belém, PA, Brazil.

${ }^{2}$ Universidade Federal Rural da Amazônia, Instituto Socioambiental e dos Recursos Hídricos, Laboratório de Genética Aplicada, Belém, PA, Brazil.

${ }^{3}$ Texas A\&M University, College of Veterinary Medicine and Biomedical Sciences, Department of Veterinary Pathobiology, Comparative Immunogenetics Laboratory, College Station, TX, USA.

${ }^{4}$ Instituto Chico Mendes de Conservação da Biodiversidade (ICMBio), Centro Nacional de Pesquisa e Conservação de Mamíferos Aquáticos (CMA), Santos, SP, Brazil.

${ }_{5}^{5}$ Instituto Chico Mendes de Conservação da Biodiversidade (ICMBio), Centro Nacional de Pesquisa e Conservação de Mamíferos Aquáticos (CMA), Itamaracá, PE, Brazil.

${ }^{6}$ Centro de Estudos e Monitoramento Ambiental (CEMAM), Areia Branca, RN, Brazil.

${ }^{7}$ Instituto Chico Mendes de Conservação da Biodiversidade (ICMBio), Centro Nacional de Pesquisa e Conservação da Biodiversidade Marinha do Norte (CEPNOR), Belém, PA, Brazil.

${ }^{8}$ Universidade da Amazônia, Parque Zoológico da UNAMA (ZOOUNAMA), Santarém, PA, Brazil.

${ }^{9}$ Texas A\&M University, Texas A\&M Health Science Center, College of Medicine, Department of Microbial Pathogenesis and Immunology, College Station, TX, USA.

\begin{abstract}
Amazonian (Trichechus inunguis) and West Indian (Trichechus manatus) manatees are aquatic mammals vulnerable to extinction found in the Amazon basin and the coastal western Atlantic. Toll-like receptors (TLR) play a key role in recognizing pathogen-associated molecular patterns using leucine-rich repeats (LRRs). We described the diversity of TLR4 and TLR8 genes in these two species of manatee. Amazonian manatee showed seven SNPs in TLR4 and the eight in TLR8, while West Indian manatee shared four and six of those SNPs, respectively. In our analysis, TLR4 showed one non-conservative amino acid replacement substitution in LRR7 and LRR8, on the other hand, TLR8 was less variable and showed only conserved amino acid substitutions. Selection analysis showed that only one TLR4 site was subjected to positive selection and none in TLR8. TLR4 in manatees did not show any evidence of convergent evolution compared to species of the cetacean lineage. Differences in TLR4 and TLR8 polymorphism may be related to distinct selection by pathogens, population reduction of West Indian manatees, or an expected consequence of population expansion in Amazonian manatees. Future studies combining pathogen association and TLR polymorphism may clarify possible roles of these genes and be used for conservation purposes of manatee species.
\end{abstract}

Keywords: Genetic diversity, Sirenian, Toll-like receptor, aquatic mammals.

Received: August 01, 2019; Accepted: January 29, 2021.

\section{Introduction}

Sirenians are herbivorous aquatic mammals distributed in tropical and subtropical regions of the Americas, western coast of Africa, and Oceania (Husar, 1977; Domning, 1981; Bonde et al., 2012), evolutionarily related to elephants (Loxodonta africana and Elephas maximus) in the Superorder Afrotheria. The Sirenia Order is represented by the Indo-Pacific dugong

Send correspondence to Michael F. Criscitiello. Texas A\&M University, College of Veterinary Medicine and Biomedical Sciences, Department of Veterinary Pathobiology, Comparative Immunogenetics Laboratory, College Station, TX 77843, USA. Email: mcriscitiello@ cvm.tamu.edu.
(Dugong dugon) and three manatee species: the West Indian (Trichechus manatus), the Amazonian (T. inunguis) and the African (T. senegalensis) manatee (Husar, 1977; Domning, 1981; Marsh and Lefebvre, 1994). The Amazonian manatee is a freshwater species found in the Amazon basin, while the West Indian manatee consists of two subspecies: the Florida manatee (T. m. latirostris) is found on the coast of United States (Texas to Massachusetts), and the Antillean manatee (T. m. manatus), from the eastern Gulf of Mexico, Caribbean, Central and South America south to northeastern Brazil (Bonde et al., 2012). An additional study using craniomorphometric characteristics and cytogenetics (Barros et al., 2016) indicates that West Indian manatees in the Brazilian coast must be a distinct species from 
the Antillean manatee. To complicate things further, evidence of hybrids of West Indian and Amazonian manatees reveals that those two species interbreed in transient habitats in the mouth of the Amazon river (Vilaça et al., 2019; Vilaça and Santos, 2020), with unknown consequences for adaptation and for the gene pool of the species involved.

All manatee species have a vulnerable conservation status according to IUCN (2019). Their decreasing numbers throughout their range is a result of past and present hunting for both meat and the leather trade (Domning, 1981), which might have affected genetic flow among populations, especially of West Indian manatees (Luna, 2013). However, the genetic diversity observed in some studies of manatees using neutral markers does not assess their ability to cope with environmental and anthropogenic changes (Garcia-Rodriguez et al., 1998; Vianna et al., 2006; Luna et al., 2012). In fact, research on pathogens afflicting manatees has been conducted both in captivity and in natural environments in order to assess their health status (Bossart et al., 1998, 2002; Bando et al., 2014; Vélez et al., 2018), but only a few genetic studies have focused on genes related to the immune response (Breaux et al., 2017, 2018; Sá et al., 2019). Thus, poorly studied innate immune genes may provide insights not only on the health status of manatees (Gelain and Bonsembiante, 2019), but also on distinct selective pressures the manatee species may have undergone in distinct habitats.

A set of relatively conserved genes involved in the innate immune response against infectious agents is the Toll-like receptors (TLRs). TLR proteins are preferentially expressed on the cell surface or endogenous membrane compartments of specialized immune cells, such as dendritic cells, macrophages and neutrophils (Fleer and Krediet, 2007; Leulier and Lemaitre, 2008; Kawai and Akira, 2010; Cervantes et al., 2012; Novák, 2014). TLRs act as pattern recognition receptors (PRR) responsible for recognizing conserved structures of pathogens, called pathogen-associated molecular patterns (PAMP), inducing the production of cytokines to orchestrate limitation or removal of infectious agents such as bacteria, viruses, protozoa and fungi, signaling a series of events that lead to inflammatory and anti-viral responses (Janeway Jr., 1989; Fleer and Krediet, 2007; Leulier and Lemaitre, 2008; Kawai and Akira, 2010; Cervantes et al., 2012; Novák, 2014; Medzhitov et al., 1997). The TLR molecule is structurally characterized by an ectodomain (ECD) containing leucine-rich repeats (LRRs) important for the recognition of PAMPs, a transmembrane domain (TM), and a cytoplasmic domain homologous to that of the interleukin-1 receptor, designated Toll/interleukin-1 receptor (TIR) domain, responsible for intracellular signaling (Fleer and Krediet, 2007; Leulier and Lemaitre, 2008; Kawai and Akira, 2010; Cervantes et al., 2012; Novák, 2014).

Most genes directly involved with innate immunity are under strong purifying selection, which is expected based on their role as the first line of defense in recognizing conserved PAMPs of various pathogens (Mukherjee et al., 2009). However, several studies on TLR genes have demonstrated polymorphism in the vertebrates investigated, including birds, humans and other wild and domesticated mammalian species (Downing et al., 2010; Alcaide and Edwards, 2011; Areal et al., 2011; Grueber et al., 2012; Shen et al., 2012; Abrantes et al., 2013; Novák, 2014; Darfour-Oduro et al., 2015; Dalton et al., 2016a,b; Ishengoma and Agaba, 2017). The majority of the functional polymorphisms are at LRR amino acids (Werling et al., 2008) while the cytoplasmic TIR domain is more conserved, probably due to its role in intracellular signaling (Werling et al., 2008).

As a first approach to study TLR in manatees we chose two functionally distinct molecules, TLR4 and TLR8. TLR4 is expressed on the cell surface and recognizes lipopolysaccharides (LPS) of primarily Gram negative bacteria (Akira et al., 2006). On the other hand, TLR8 is located on the endosomes and detects viral nucleic acids (Akira et al., 2006; Barton, 2007; Yoneyama and Fujita, 2010). The aim of this study were to describe the diversity of TLR 4 and TLR 8 in Brazilian populations of T. manatus and T. inunguis.

\section{Material and Methods}

\section{Samples}

In this study we used 17 T. manatus of the National Center for Research and Conservation of Aquatic Mammals (CMA) of the Chico Mendes Institute for Biodiversity Conservation (ICMBio), Itamaracá, Pernambuco, Brazil, and 26 T. inunguis from the ZOOUNAMA (Santarém, Pará, Brazil), mostly born in the wild (Figure 1, detailed information on samples is in Table S1). All procedures were approved by the UFPA Ethics Committee under the permit CEUA/UFPA, CEPAE 68-2015. Blood sampling was performed by trained and authorized personnel under the license SISBIO 50641-2.

\section{TLR amplification and sequencing}

DNA was extracted from peripheral blood leukocytes with the DNeasy Tissue \& Blood kit (Qiagen; Hilden, Germany) following the manufacturer's protocol. We used Primer-BLAST (https://blast.ncbi.nlm.nih.gov/Blast.cgi) and SerialCloner 2.6.1 (http://serialbasics.free.fr/) to design primers for the amplification of exon 1 of TLR4 (2,242 bp) and the entire TLR 8 sequence (3,081 bp), which corresponds to a single exon, using the T. manatus latirostris TLR4 (GI: 101353470) and TLR8 (GI: 101348463) genes from the NCBI (National Center for Biotechnology Information) genomic database. Due to size restrictions for sequencing, we developed an amplification assay with overlapping amplicons, using multiple primer pairs (Table S2). Target exons were PCR amplified with the GoTaq ${ }^{\circledR F}$ Flexi DNA Polymerase kit and GoTaq ${ }^{\circledR}$ Green Master Mix (Promega, Madison, USA), according to the manufacturer's instructions. The PCR consisted of an initial denaturation step at $95^{\circ} \mathrm{C}$ for $5 \mathrm{~min}$, followed by 35 cycles of $95{ }^{\circ} \mathrm{C}$ for $1 \mathrm{~min}$; optimum annealing temperature for each primer pair for $1 \mathrm{~min}$ (Table S2); $72{ }^{\circ} \mathrm{C}$ for $1 \mathrm{~min}$, and final extension at $72{ }^{\circ} \mathrm{C}$ for $7 \mathrm{~min}$.

The PCR products were Sanger sequenced (Applied Biosystems 3730 DNAAnalyzer and 3500 Genetic Analyzer) in both directions, with the BigDye $(\mathrm{X}$ Terminator v3.1. kit (Applied Biosystems, Carlsbad, USA). Sequences were concatenated to form contigs for each sample; sequences were checked individually in Sequencer 4.1 (Gene Codes). Contigs were submitted to the National Center for Biotechnology Information (accession numbers are in Table S3). Sampled full length contigs were aligned using MAFFT online service (Katoh et al., 2017). Intron sequences were removed from our 


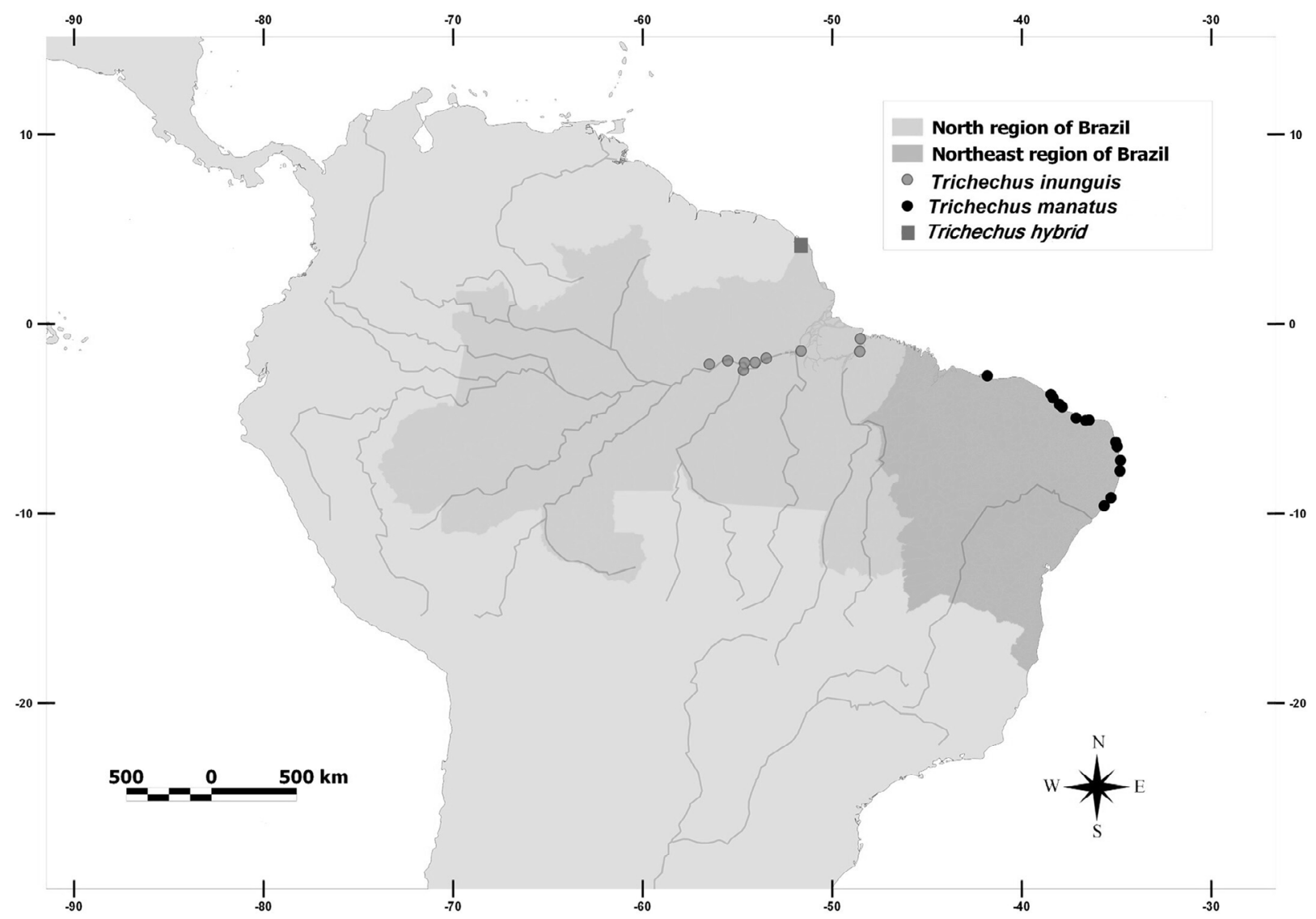

Figure 1 - Map indicating the respective geographic collection sites of the manatees in North and Northeast regions of Brazil.

database. For the concatenated sequences, diploid genotypes were phased using Phase v2.1 implemented in DnaSP (Librado and Rozas, 2009), using 5,000 iterations with a burn-in of 500. Due to the size of amplicons, sequence quality was low in some individuals in the extremities of amplicons; in cases where low sequence quality hampered clear resolution of nucleotides in the overlapping region of amplicons, "Ns" were used in the alignments. Those "Ns" prevented a total overlapping for the TLR8 amplicons; thus, TLR8 sequences were analyzed as different segments - and we could only do phase analysis for each segment separately.

\section{TLR diversity and natural selection}

We examined TLR sequences for evidence of selection using the HyPhy package46, implemented in the Datamonkey server (https://www.datamonkey.org/; Delport et al., 2010) utilizing phased haplotypes obtained via DNAsp. We looked for evidence of positive selection using the mixed effects model of evolution (MEME), the more conservative single-likelihood ancestral counting (SLAC) method and unconstrained Bayesian aproximation for inferring selection (FUBAR) (Kosakovsky Pond and Frost, 2005; Murrell et al., 2012; Murrell et al., 2013). MEME uses a mixed-effects maximum likelihood approach to determine nonsynonymous $\left(\mathrm{d}_{\mathrm{N}}\right)$ and synonymous $\left(d_{\mathrm{s}}\right)$ substitution rates to detect episodic positive or diversifying selection at individual sites; SLAC calculates the expected and observed numbers of synonymous and nonsynonymous substitutions to infer selection and is a conservative test; and
FUBAR is similar to SLAC but uses a Bayesian approach. We also analyzed other algorithms focusing on the gene locus. Thus, we compared Sirenians, Afrotherians and Artiodactyls, using BUSTED, which identifies genetic evidence of episodic positive selection, in which the rate of non-synonymous substitution is greater than the reason by the synonymous (Murrell et al., 2015); RELAX, a framework hypothesis test that detects relaxed selection in a codon-based phylogenetic framework (Wertheim et al., 2014); and the aBSREL, a random effect branch-site model (Pond et al., 2011; Smith et al., 2015). Accession numbers are provided in Table S4.

Shen et al. (2012) estimated TLR4 sites under positive selection in the cetacean clade, another lineage of aquatic mammals not related to sirenians. In order to evaluate those two lineages of aquatic mammals, we compared those sites under positive selection in cetaceans to the homologues of sirenians. We also included in this analysis cattle and African elephant as related terrestrial mammals to cetaceans and manatees, respectively. This comparative analysis could not be performed for TLR8.

\section{TLR structure analysis}

We used the amino acid sequences of the T. $\mathrm{m}$. latirostris TLR4a and TLR4b isoforms (XP 004372178.2 and XP_012409812.1) and TLR8 (XP_004386403.1) from NCBI to identify the conserved domains by LRRfinder (Offord and Werling, 2012; http://www.lrrfinder.with/) and SMART (http://smart.embl-heidelberg.de/). 


\section{Results}

\section{Identification of TLR 4 and 8 polymorphisms}

In the manatees, TLR 4 and TLR 8 had 20 and 22 LRRs, respectively. The frequency of the TLR4 SNPs varied between both species of manatees, but the number of SNPs were higher in Amazonian manatee in comparison to West Indian manatee for both TLR4 and TLR8, with no exclusive SNP for the latter species (Figures 2 and 3). Thus, both species shared four TLR4 SNPs: one synonymous substitution in LRR10 and one in TIR, one conservative non-synonymous substitution in LRR8 [Ala to Gly (nonpolar, hydrophobic)], and one non-conservative non-synonymous replacement in LRR7 [Glu (polar, hydrophilic, neutral) to Arg (polar, hydrophilic, basic)]. The remaining TLR4 SNPs were exclusive of the Amazonian manatee: one synonymous substitution in LRR15 and another in TIR, and one non-conservative non-synonymous replacement in TIR [Lys (polar, hydrophilic, basic) to Met (nonpolar hydrophobic)]. For TLR8, both species shared synonymous substitutions in LRR2, LRR8, LRR13 and LRR14, and conservative non-synonymous substitutions in LRR3, and between the TM and TIR domains with amino acid change from methionine to valine (nonpolar, hydrophobic) in both SNPs. In addition, Amazonian manatee showed two additional synonymous substitutions in LRR1.

The hybrid sample (Tman45) showed nucleotide sequences of TLR4 and TLR8 that are compatible with those found in West Indian manatee, i.e. it did not show any nucleotides that were exclusive for Amazonian manatee. Hence, we could not say whether this sample was a hybrid of the both manatee species studied based on TLR4 and TLR8 polymorphism (Table S5 and Table S6).

\section{Positive selection}

Estimates for MEME and SLAC did not detect any site under selection for either TLR4 or TLR8 in our manatee samples. However, FUBAR analysis indicated one candidate site for positive selection (position 608 in our database) corresponding to the TIR domain of and three for negative selection (position 261, 621 and 713 in our database) in $T$. inunguis for TLR4, in the LRR10 and two in TIR region. The site under positive selection is equivalent to position 183 when compared to cetaceans (Shen et al., 2012; Table 1). In T. manatus, no site under positive selection was identified. In addition to the test for sites under selection, we tested whether the TLR sequences as a whole show evidence of selection by using the ABSREL, BUSTED and RELAX methods. RELAX was run with the sequences of Afrotherians and terrestrial Artiodactyls as the reference set to evaluate the selection intensification in the sequences of aquatic mammals. However, no evidence of positive selection was found for sirens, only RELAX suggested intensification in the selection in cetaceans for TLR8. Because there were few sites varying between both manatee species we compared them to the ones under positive selection in cetaceans according to Shen et al. (2012). Cetaceans corresponded to several species, while in manatee there were only two species. Our first approach was to compare TLR4 in West Indian manatee to its closest terrestrial relative, the African elephant. In this comparison, five positions revealed distinct amino acids (in bold in Table 1); then, we compared those five sites to the ones found in cetaceans and a close terrestrial relative, cattle, where we found that two of those sites had the same amino acids in cattle and manatee. Thus, from the three remaining sites in manatees that were different from African elephant, none of

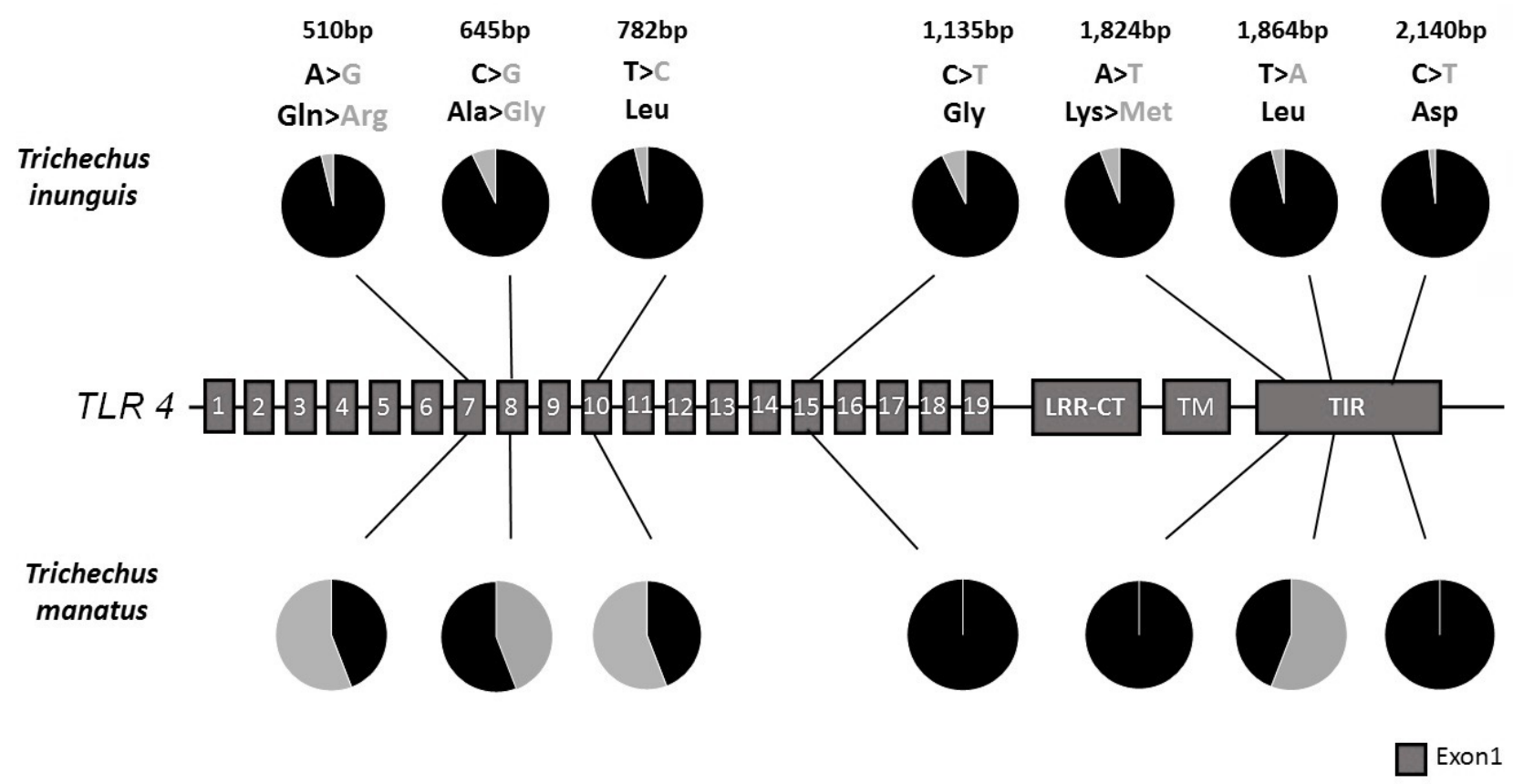

Figure 2 - Identification of SNPs in the structure of the TLR4 gene. In the graph the higher frequency of nucleotides is represented in black with synonymous and non-synonymous occurrences in two populations of manatees. The cartoon structure is represented by exon 1 (red). Rectangles represent LRRs (1-19), LRR-CT, trans-membrane (TM) and intracellular (TM) domains. 


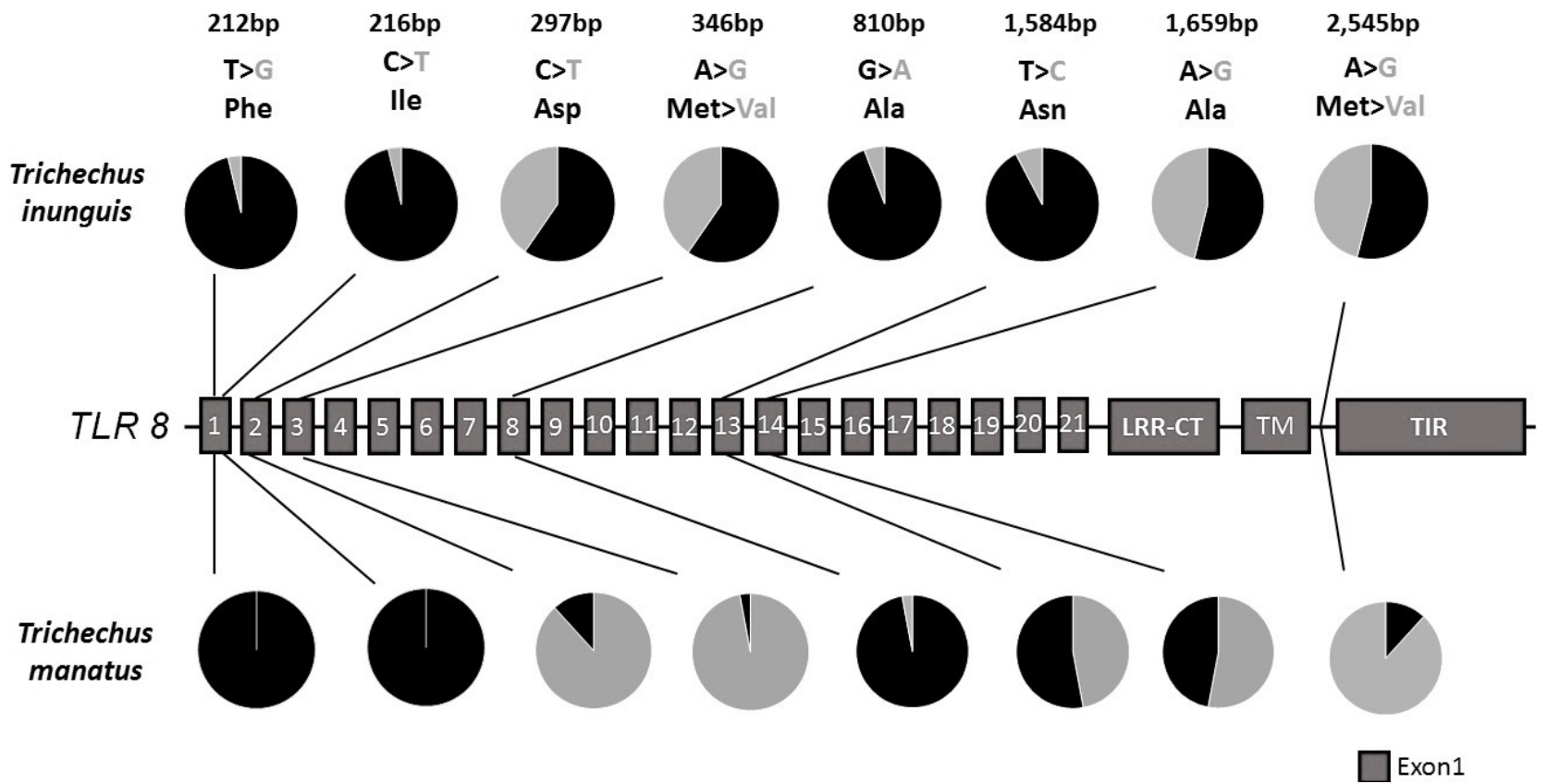

Figure 3 - Identification of SNPs in the structure of the TLR8 gene. In the graph the higher frequency of nucleotides is represented in black with synonymous and non-synonymous occurrences in two populations of manatees. The cartoon structure is represented by exon 1 (red). Rectangles represent LRRs (1-21), LRR-CT, trans-membrane (TM) and intracellular (TM) domains.

Table 1 - Positive selection at amino acid sites of cetaceans according to Shen et al. (2012) in comparison to manatee, elephant, and cattle forTLR4 using FUBAR method. In bold, amino acids that are different between Florida manatee and African elephant.

\begin{tabular}{cccccc}
\hline AA position & Domain & Florida manatee & African Elephant & Cetaceans & Cattle \\
\hline 108 & LRR6 & His & His & Gln/Arg/His & His \\
128 & LRR6 & Gln & Gln & Glu/Pro & Glu \\
$\mathbf{1 5 0}$ & Between LRR6-LRR7 & Asn & Thr & His/Arg & His \\
177 & LRR7 & Asn & Asn & Ile/Thr/Asn & Lys \\
179 & LRR7 & Asp & Asp & Lys/Glu/Gln & Gln \\
183 & LRR7 & Lys & Lys & Arg/Ser/Thr & Arg \\
207 & LRR8 & Ser & Ser & Lys/Thr/Arg & Gly \\
$\mathbf{2 0 8}$ & LRR8 & Asn & His & Asp/Ser & Asp \\
221 & Between LRR8-LRR9 & Ala & Ala & Val/Ala/Met & Val \\
228 & LRR9 & Asp & Asp & Asn/Asp & Ser \\
$\mathbf{2 7 2}$ & LRR11 & Asp & Asn & His/Gly & Asp \\
$\mathbf{2 7 8}$ & LRR11 & Asp & Glu & Glu/Asp/Lys & Glu \\
308 & LRR12 & Thr & Thr & Thr/Ile/Ser & Thr \\
$\mathbf{3 2 4}$ & LRR13 & Gly & Asn & His/Asn/Ser/Lys & Gly \\
\hline
\end{tabular}

them had the same amino acids as the cetaceans studied by Shen et al. (2012). Thus, there was no evidence of convergent evolution in TLR4 between cetaceans and sirenians.

\section{Discussion}

Four out of seven SNPs found in the TLR 4 and six out of eight SNPs found in TLR8 of the Amazonian manatees were found in the West Indian manatee samples studied here. This higher level of variability in the Amazonian manatee genes could be related to distinct and more diversified pathogens found in fresh water habitats (Lang et al., 2009), or be another indication of population expansion signatures of this species as evidenced in other studies (Vianna et al., 2006), or may suggest that West Indian manatees have lost part of their variability due to recent decrease in population numbers, that could have affected at least some TLR genes, which could have conservation implications for both species.

The hybrid specimen analyzed here could not be differentiated from a West Indian manatee. This hybrid individual was studied by Luna (2013) and, although it had morphological characteristics of a West Indian manatee, its mitochondrial DNA is of an Amazonian manatee, while its karyotype had an intermediate number of chromosomes $(n=50)$ between West Indian $(n=48)$ and Amazonian $(n-56)$ manatee. Although no conclusion may be drawn from only one hybrid individual, it reminds us of the importance of studying hybridization in manatees (Vilaça et al., 2019; Vilaça and Santos, 2020) and to evaluate the relative contribution 
of TLR polymorphism on the adaptation of those hybrids. As has been evidenced in some studies, TLR genes are to a great extent subjected to purifying selection (Alcaide and Edwards, 2011; Areal et al., 2011; Shen et al., 2012; Ishengoma and Agaba, 2017). When analyzing the levels of TLR polymorphism in human and chimpanzee populations, contrasted with the variation in the broader primate lineage, the TLR evolutionary pattern indicates that more episodic events of pathoghen-driven evolution have acted on a large time scale than ongoing selection in shorter periods (Wlasiuk and Nachman, 2010). In our manatee samples, TLR4 showed one non-conservative amino acid replacement substitution in LRR7 and LRR8, although clear signals of positive selection were not observed except in a position correspondent to the TIR domain of TLR4. TLR8, on the other hand, was less variable and showed only conserved amino acid substitutions. This pattern of higher variability in TLR4 and lower in TLR8 was also observed for other mammals (Kloch et al., 2018) and birds (Alcaide and Edwards, 2011; Dalton et al., 2016a), which may be attributed to the distinct pathogens each TLR identifies (Uematsu and Akira 2006), with TLR8 recognizing PAMPs in virus that must be less subjected to selection associated pathogen-host interactions (Kloch et al., 2018).

As stated before, only one site of TLR4 was subjected to positive selection and none in TLR8 in manatees. On the other hand, in the primate lineage, TLR4 shows the highest values of positive selection among other TLR genes (Wlasiuk and Nachman, 2010; Kloch et al., 2018). In cetaceans, TLR4 also reveals several sites under positive selection (Areal et al., 2011; Shen et al., 2012; Ishengoma and Agaba, 2017). However in cetaceans several different species were compared in Shen et al. (2012), while in sirenians only two closely related species were analyzed in our study. Notwithstanding, the lack of convergent evolution in the TLR4 sites under positive selection in cetaceans in comparison to sirenians may be attributed not only to differences in the pathogens found in their environment (Shen et al., 2012), but with other ecological variables, mainly the exclusive herbivory of manatees, which makes it less likely for them to come into contact with different pathogens and commensals found in cetacean preys (Ishengoma and Agaba, 2017). Thus, although several lineages of marine mammals show evidence of convergent evolution (Tenaillon et al., 2012; Stern, 2013; Foote et al., 2015; Chikina et al., 2016), it might be more difficult to find similarities in immune response between highly divergent groups of aquatic mammals.

In conclusion, West Indian and Amazonian manatees showed polymorphism in TLR4 and TLR8, with higher variability in the latter. It is unclear at this moment whether differences in polymorphism are related to distinct selection by pathogens, population reduction of West Indian manatees, or an expected consequence of population expansion in Amazonian manatees. Genes related to innate immune response, such as TLR, may be good candidates for screening to assess manatee health status and evaluate the importance of their hybridization zone, as well as their conservation status. Future studies combining pathogen association and TLR polymorphism may clarify possible roles of these genes and be used for conservation purposes of manatee species.

\section{Acknowledgments}

We thank Davi César Nascimento and Soraya da Silva Andrade for technical assistance with Sanger sequencing. This work was funded by Federal University of Pará and Texas A\&M CAPES Collaborative Research. Samples were obtained from the National Center for Research and Conservation of Aquatic Mammals (CMA) of the Chico Mendes Institute for Biodiversity Conservation (ICMBio) and ZOOUNAMA. All procedures were approved by the ethical committee under the permit in Brazil as CEUA/UFPA, CEPAE 68-2015 and blood sampling under the license SISBIO 50641-2.

\section{Conflict of Interest}

The authors have no financial relationships relevant to this article to disclose, and they declare that there is no conflict of interest.

\section{Author Contributions}

TO, LS, MC and MS conceived of the study. TO conducted all the experiments. TO, AS, TB, LS, BB, MC and MS analyzed the data. AS, LS, MC and MS supervised all analyse. FL, FA, AK and JO collected samples. TO, AS, LS, MC and MS prepared the manuscript. All authors read and approved the final version.

\section{References}

Abrantes J, Areal H and Esteves PJ (2013) Insights into the European rabbit (Oryctolagus cuniculus) innate immune system: genetic diversity of the toll-like receptor 3 (TLR3) in wild populations and domestic breeds. BMC Genet 14:1-7.

Akira S, Uematsu S and Takeuchi O (2006) Pathogen recognition and innate immunity. Cell 124:783-801.

Alcaide M and Edwards S V. (2011) Molecular evolution of the toll-like receptor multigene family in birds. Mol Biol Evol 28:1703-1715.

Areal H, Abrantes J and Esteves PJ (2011) Signatures of positive selection in Toll-like receptor (TLR) genes in mammals. BMC Evol Biol 11:368.

Bando M, Larkin I V, Wright SD and Greiner EC (2014) Diagnostic Stages of the Parasites of the Florida Manatee, Trichechus Manatus Latirostris. J Parasitol 100:133-138.

Barros HMD d. R, Meirelles ACO, Luna FO, Marmontel M, Cordeiro-Estrela P, Santos N and Astúa D (2016) Cranial and chromosomal geographic variation in manatees (Mammalia: Sirenia: Trichechidae) with the description of the Antillean manatee karyotype in Brazil. J Zool Syst Evol Res 55:73-87.

Barton GM (2007) Viral recognition by Toll-like receptors. Semin Immunol 19:33-40.

Bonde RK, Mcguire PM and Hunter ME (2012) A review of the key genetic tools to assist imperiled species conservation: analyzing West Indian manatee populations. J Mar Anim Their Ecol 5:8-19.

Bossart GD, Baden DG, Ewing RY, Roberts B and Wright SD (1998) Brevetoxicosis in manatees (Trichechus manatus latirostris) from the 1996 epizootic: gross, histologic, and immunohistochemical features. Toxicol Pathol 26:276-282.

Bossart GD, Ewing RY, Lowe M, Sweat M, Decker SJ, Walsh CJ, Ghim S and Jenson AB (2002) Viral papillomatosis in Florida manatees (Trichechus manatus latirostris). Exp Mol Pathol 72:37-48. 
Breaux B, Deiss TC, Chen PL, Cruz-Schneider MP, Sena L, Hunter ME, Bonde RK and Criscitiello MF (2017) The Florida manatee (Trichechus manatus latirostris) immunoglobulin heavy chain suggests the importance of clan III variable segments in repertoire diversity. Dev Comp Immunol 72:57-68.

Breaux B, Hunter ME, Cruz-Schneider MP, Sena L, K.Bonde R and F.Criscitiell M(2018) The Florida manatee (Trichechus manatus latirostris) $\mathrm{T}$ cell receptor loci exhibit $\mathrm{V}$ subgroup synteny and chain-specific evolution. Dev Comp Immunol 85:71-85.

Cervantes JL, Weinerman B, Basole C and Salazar JC (2012) TLR8: the forgotten relative revindicated. Cell Mol Immunol 9:434-438.

Chikina M, Robinson JD and Clark NL (2016) Hundreds of genes experienced convergent shifts in selective pressure in marine mammals. Mol Biol Evol 33:2182-2192.

Dalton DL, Vermaak E, Smit-robinson HA and Kotze A (2016a) Lack of diversity at innate immunity Toll-like receptor genes in the critically endangered White-winged Flufftail (Sarothrura ayresi). Nat Publ Gr 6:1-8.

Dalton L, Vermaak E, Roelofse M and Kotze A (2016b) Diversity in the Toll-Like receptor genes of the African penguin (Spheniscus demersus). PLoS One 10:1-12.

Darfour-Oduro KA, Megens HJ, Roca AL, Groenen MAM and Schook LB (2015) Adaptive evolution of Toll-like receptors (TLRs) in the family Suidae. PLoS One 10:1-16.

Delport W, Poon AFY, Frost SDW and Kosakovsky Pond SL (2010) Datamonkey 2010: A suite of phylogenetic analysis tools for evolutionary biology. Bioinformatics 26:2455-2457.

Domning DP (1981) Distribution and status of manatees Trichechus spp. near the mouth of the Amazon River, Brazil. Biol Conserv 19:85-97.

Downing T, Lloyd AT, Farrelly CO and Bradley DG (2010) The differential evolutionary dynamics of avian cytokine and TLR gene classes. J Immunol 13:6994-7000.

Fleer A and Krediet TG (2007) Innate immunity: Toll-like receptors and some more - A brief history, basic organization and relevance for the human newborn. Neonatology 92:145-157.

Foote AD, Liu Y, Thomas GWC, Vinař T, Alföldi J, Deng J, Dugan S, van Elk CE, Hunter ME, Joshi V et al. (2015) Convergent evolution of the genomes of marine mammals. Nat Genet 47:272-5.

Garcia-Rodriguez AI, Bowen BW, Domning D, Mignocci-Giannonl AA, Marmontel M, Montoya-Ospina RA, Mrales-Vela B, Rudin M, Bonde RK and McGuire PM (1998) Phylogeography of the West Indian manatee (Trichechus manatus): how many populations and how many taxa? Mol Ecol 7:1137-1149.

Gelain ME and Bonsembiante F (2019) Acute phase proteins in marine mammals: State of art, perspectives and challenges. Front Immunol 10:1-8.

Grueber CE, Wallis GP, King TM and Jamieson IG (2012) Variation at innate immunity Toll-like receptor genes in a bottlenecked population of a New Zealand robin. PLoS One 7:1-7.

Husar ST (1977) West Indian manatee (Trichechus manatus). Fish Wildl Serv 145.

Ishengoma E and Agaba M (2017) Evolution of Toll-like receptors in the context of terrestrial ungulates and cetaceans diversification. BMC Evol Biol 17:1-13.

Janeway CA Jr. (1989) Approaching the asymptote? Evolution and revolution in immunology. Cold Spring Harb Symp Quant Biol 54:1-13.

Katoh K, Rozewicki J and Yamada KD (2017) MAFFT online service : multiple sequence alignment, interactive sequence choice and visualization. Brief Bioinform 20:1160-1166.

Kawai T and Akira S (2010) The role of pattern-recognition receptors in innate immunity: update on Toll-like receptors. Nat Immunol $11: 373-384$
Kloch A, Wenzel MA, Laetsch DR, Michalski O, Welc-Falęciak R and Piertney SB (2018) Signatures of balancing selection in toll-like receptor (TLRs) genes - novel insights from a freeliving rodent. Sci Rep 8:1-10.

Kosakovsky Pond SL and Frost SDW (2005) Not so different after all: A comparison of methods for detecting amino acid sites under selection. Mol Biol Evol 22:1208-1222.

Lang AS, Rise ML, Culley AI and Steward GF (2009) RNA viruses in the sea. FEMS Microbiol Rev 33:295-323.

Leulier F and Lemaitre B (2008) Toll-like receptors - taking an evolutionary approach. Nature 9:165-178.

Librado P and Rozas J (2009) DnaSP v5: a software for comprehensive analysis of DNA polymorphism data. Bioinforma Appl Note 25:1451-1452.

Luna FO (2013) Population genetics and conservation strategies for the West Indian manatee (Trichechus manatus Linnaeus, 1758 ) in Brazil. Doctoral thesis, Universidade Federal de Pernambuco.

Luna FO, Bonde RK, Attademo FLN, Saunders JW, Meigs-Friend G, Passavante JZO and Hunter ME (2012) Phylogeographic implications for release of critically endangered manatee calves rescued in Northeast Brazil. Aquat Conserv Mar Freshw Ecosyst 22:665-672.

Marsh H and Lefebvre LW (1994) Sirenian status and conservation efforts. Aquat Mamm 20:150-170.

Medzhitov R, Preston-Hurlburt P and Janeway CA Jr (1997) A human homologue of the Drosophila Toll protein signals activation of adaptive immunity. Nature 388:394-397.

Mukherjee S, Sarkar-Roy N, Wagener DK and Majumder PP (2009) Signatures of natural selection are not uniform across genes of innate immune system, but purifying. Proc Natl Acad Sci U S A 106:7073-7078.

Murrell B, Moola S, Mabona A, Weighill T, Sheward D, Kosakovsky Pond SL and Scheffler K (2013) FUBAR: A fast, unconstrained bayesian approximation for inferring selection. Mol Biol Evol 30:1196-1205.

Murrell B, Wertheim JO, Moola S, Weighill T, Scheffler K and Kosakovsky Pond SL (2012) Detecting individual sites subject to episodic diversifying selection. PLoS Genet 8:e1002764.

Murrell B, Weaver S, Smith MD, Wertheim JO, Murrell S, Aylward A, Eren K, Pollner T, Martin DP, Smith DM et al. (2015) Gene-wide identification of episodic selection. Mol Biol Evol 32:1365-1371.

Novák K (2014) Functional polymorphisms in Toll-like receptor genes for innate immunity in farm animals. Vet Immunol Immunopathol 157:1-11.

Offord V and Werling D (2012) LRRfinder2.0: A webserver for the prediction of leucine-rich repeats. Innate Immun 19:398-402.

Pond SLK, Murrell B, Fourment M, Frost SDW, Delport W and Scheffler K (2011) A random effects branch-site model for detecting episodic diversifying selection. Mol Biol Evol 28:3033-3043.

Sá ALA, Breaux B, Burlamaqui TCT, Deiss TC, Sena L, Criscitiello MF and Cruz Schneider MP (2019) The marine mammal class II major histocompatibility complex organization. Front Immunol 10:1-14.

Shen T, Xu S, Wang X, Yu W, Zhou K and Yang G (2012) Adaptive evolution and functional constraint at TLR4 during the secondary aquatic adaptation and diversification of cetaceans. BMC Evol Biol 12:12-39.

Smith MD, Wertheim JO, Weaver S, Murrell B, Scheffler K and Kosakovsky Pond SL (2015) Less is more: An adaptive branch-site random effects model for efficient detection of episodic diversifying selection. Mol Biol Evol 32:1342-1353.

Stern DL (2013) The genetic causes of convergent evolution. Nat Rev Genet 14:751-764. 
Tenaillon O, Rodríguez-Verdugo A, Gaut RL, McDonald P, Bennett AF, Long AD and Gaut BS (2012) The molecular diversity of adaptive convergence. Science 335:457-461.

Uematsu S and Akira S (2006) Toll-like receptors and innate immunity. J Mol Med (Berl) 84:712-25.

Vélez J, Hirzmann J, Lange MK, Chaparro-Gutiérrez JJ, Taubert A and Hermosilla C (2018) Occurrence of endoparasites in wild Antillean manatees (Trichechus manatus manatus) in Colombia. Int J Parasitol Parasites Wildl 7:54-57.

Vianna JA, Bonde RK, Caballero S, Giraldo JP, Lima RP, Clark A, Marmontel M, Morales-Vela B, De Souza MJ, Parr L et al. (2006) Phylogeography, phylogeny and hybridization in trichechid sirenians: Implications for manatee conservation. Mol Ecol 15:433-447.

Vilaça ST, Lima CS, Mazzoni CJ, Santos FR and de Thoisy B (2019) Manatee genomics supports a special conservation area along the Guianas coastline under the influence of the Amazon River plume. Estuar Coast Shelf Sci 226:106286.

Vilaça ST and Santos FR (2020) Complete mitochondrial genome of the florida manatee (Trichechus manatus latirotris, Sirenia). Genet Mol Biol 42:1-4.

Werling D, Jann OC, Offord V, Glass EJ and Coffey TJ (2008) Variation matters: TLR structure and species-specific pathogen recognition. Trends Immunol 30:124-130.

Wertheim JO, Murrell B, Smith MD, Pond SLK and Scheffler K (2014) RELAX: Detecting relaxed selection in a phylogenetic framework. Mol Biol Evol 32:820-832.

Wlasiuk G and Nachman MW (2010) Adaptation and constraint at Toll-like receptors in primates. Mol Biol Evol 27:2172-2186.

Yoneyama M and Fujita T (2010) Recognition of viral nucleic acids in innate immunity. Rev Med Virol 20:4-22.

\section{Internet Resources}

DataMonkey web server, https://www.datamonkey.org (accessed 3 April 2019).
IUCN (2019) IUCN Red List of Threatened Species, http://www. iucnredlist.org (accessed 9 July 2019).

LRRfinder, http://www.lrrfinder.with/ (accessed 20 June 2018).

MAFFT, http://mafft.cbrc.jp/alignment/server/large.html (accessed 10 April 2018).

Primer-BLAST, https://blast.ncbi.nlm.nih.gov/Blast.cgi (accessed 22 July 2016).

SMART, http://smart.embl-heidelberg.de/ (accessed 10 May 2018).

\section{Supplementary material}

The following online material is available for this article:

Table S1 - Information of samples collected in two manatee species from Brazil.

Table S2 - Amplified fragments of each TLR.

Table S3-Accession number of TLR4 and TLR8 sequences in Amazonian and West Indian manatees deposited in GenBank. Table S4 - Accession numbers of the TLR4 and TLR8 from GenBank.

Table S5 - Identification of SNPs for the TLR4 in Amazonian (Trichechus inunguis) and West Indian (Trichechus manatus) manatees.

Table S6 - Identification of SNPs for the TLR8 in Amazonian (Trichechus inunguis) and West Indian (Trichechus manatus) manatees.

License information: This is an open-access article distributed under the terms of the Creative Commons Attribution License (type CC-BY), which permits unrestricted use, distribution and reproduction in any medium, provided the original article is properly cited. 